ms_Text_final version

26 December 2014

\title{
Multi Criteria Analysis for the monitoring of aquifer vulnerability: a scientific tool in environmental policy
}

\author{
Valle Junior, R.F.do ${ }^{1}$, Varandas, S.G.P. ${ }^{1}$, Sanches Fernandes, L.F. ${ }^{1}$, Pacheco, F.A.L. ${ }^{2 *}$ \\ ${ }^{1}$ Centre for Research and Technology of Agro-Environment and Biological Sciences, \\ University of Trás-os-Montes and Alto Douro, Vila Real, Portugal \\ ${ }^{2}$ Department of Geology and Chemistry Research Center, \\ University of Trás-os-Montes and Alto Douro, Vila Real, Portugal
}

*Corresponding author: fpacheco@utad.pt

(C) 2015. This manuscript version is made available under the Elsevier user license http://www.elsevier.com/open-access/userlicense/1.0/ 


\section{ABSTRACT}

The vulnerability of a fractured aquifer was quantified in the River Sordo basin (northeast Portugal) to check the risk of groundwater contamination in that watershed. Vulnerability was evaluated by Multi Criteria Analysis (MCA) and compared with DRASTIC results. MCA revealed a predominance of electrical conductivity, sulphate and copper as indicators of aquifer vulnerability. DRASTIC showed the highest vulnerabilities in areas covered by alluvium and where granites and metassediments come into contact. A comparison of results by cross tabulation using GIS confirmed that over $96 \%$ of the basin is invulnerable or weakly vulnerable to groundwater contamination. The conformity of actual to natural land uses explains the self ability of the basin to control groundwater quality and be in a status of hydrological sustainability. River Sordo ground waters drain to a dam lake which is the source of drinking water to 50000 people. The lake water is in a very good status, in conformity with the Directive $n^{\circ} 2000 / 60 / E C$. The multi criteria analysis is more expeditious in the diagnosis of vulnerability, not considering the hydrogeological, geomorphologic and soil characteristics of the basin required for the application of DRASTIC. The MCA and the DRASTIC were defined as analogue approaches, with the DRASTIC being classified as reference and the MCA as monitoring method. The combined application of DRASTIC and MCA was found crucial for the inclusion of aquifer vulnerability as topic in the framework of groundwater quality protection programs.

Keywords: Multi Criteria Analysis, DRASTIC, aquifer vulnerability, groundwater contamination, environmental policy, hydrological sustainability. 
ms_Text_final version

26 December 2014

\section{INTRODUCTION}

The estimation of aquifer vulnerability is critical for the implementation of ground water quality protection programs. Over the last decades, a variety of methods for the modelling and mapping of aquifer vulnerability have been developed, with the aim of assisting decision making (e.g. Focazio et al. 2005). Usually, these methods consider similar factors but may use different approaches for data integration, being grouped into four categories: lumped parametric indices (Aller et al. 1987), statistical procedures (Masetti et al. 2009; Sorichetta et al. 2011), process-based algorithms (Neukum and Azzam 2009), and/or a combination of these methods (Yu et al. 2010). In all cases, the modeling involves integration of hydrogeological (e.g. recharge), geomorphologic (e.g. terrain relief) and soil characteristics, and requires large datasets for execution. For this reason, the assessment of aquifer vulnerability by standard methods is costly and time consuming. Because of its high cost, standard aquifer vulnerability maps tend to be static documents, valid solely for the moment of their elaboration, failing to account for the temporal evolution of specific vulnerability resulting from changes in the land use of the target areas. In the end, these maps may become useless in the outline of groundwater quality management policies. To circumvent this setback, the actuality of conventional aquifer vulnerability maps could be monitored by analogue maps elaborated by expeditious methods based on easily collectable data. A low cost pathway towards aquifer vulnerability monitoring could be the use of specific groundwater quality parameters as vulnerability indicators, for example the concentrations of nitrate and sulphate in areas dominated by agriculture (Huan et al. 2012; Javadi et al. 2011a,b; Neshat et al. 2014; Panagopoulos et al. 2006). In this case, the sole data required for the study of vulnerability would be the chemical analyses of groundwater samples. The tool to process this data could be the Multi Criteria Analysis (MCA) as because this technique proved efficient in other studies of groundwater contamination (Rezaei et al. 2012) as well as in studies of solute transport (Dou et al. 1999), 
ms_Text_final version

26 December 2014

environmental assessment (Garfi et al. 2011), or water resources management (Chowdhury and Rahman 2008). MCA includes the definition and standardisation of environmental factors that are relevant to the problem, followed by its weighted linear combination.

Standardisation is accomplished by fuzzy logic whereby the original factors are converted into scores that are calculated by a probability function (Jiang and Eatman 2000). Weighted linear combination is a sum of standardized scores, previously multiplied by predefined weights (Eastman 2012).

A number of studies integrated standard aquifer vulnerability maps with groundwater quality parameters to study the risk of groundwater contamination (e.g. Huan et al. 2012; Wang et al. 2012). But the purpose was never the establishment of a framework where the standard map could be updated at short time intervals by an expeditious analogue map. The objective of this work is to take that step forward, by coupling the estimation of aquifer vulnerability by a standard method with its evaluation by MCA, verifying the reliability of using the two approaches as analogues. As the DRASTIC (Aller et al. 1987) is commonly used for determining aquifer vulnerability, it will be adopted as standard in this study.

\section{AREA OF STUDY}

The hydrographic basin of River Sordo, which is integrated in the large River Douro basin where the famous Port Wine is produced, is located in the region of Trás-os-Montes and Alto Douro, in northeast Portugal. With an area of approximately $50 \mathrm{~km}^{2}$, the River Sordo basin is a radial shape catchment situated between the northern latitudes of $41^{\circ} 16^{\prime} 05.57^{\prime \prime}-41^{\circ} 20^{\prime} 12.81^{\prime \prime}$ and western longitudes of $7^{\circ} 55^{\prime} 21.82^{\prime \prime}-7^{\circ} 45^{\prime} 42.45^{\prime \prime}$, covering a large portion of the Vila Real municipality (Figure 1). 
The River Sordo is a right margin tributary of River Corgo that debouches into River Douro. It is a mountainous river of the Marão cordillera where the altitudes vary between 300 and 1100 meters above sea level, the annual precipitation exceeds $1000 \mathrm{~mm} \cdot \mathrm{yr}^{-1}$, and the mean annual temperature approaches $14^{\circ} \mathrm{C}$. The main watercourse is approximately 20 $\mathrm{km}$ long and, in combination with its tributaries, forms a dendritic drainage network. Slopes are gentle along streams $(<10 \%)$, especially in the central area where the landscape is characterised by an ample undulated valley $(<5 \%)$, being steep $(>30 \%)$ in the adjacent hillsides and along water divides of the western limits. A region of very steep slopes is also observed at the mouth of the river basin (Figure 1).

The geologic setting is characterised by crystalline rocks composed of Palaeozoic metassediments intruded by Hercynian granites, covered in the central area (Campeã valley) by alluvial deposits extending over an area of approximately $3.2 \mathrm{~km}^{2}$. In the region where the basin widens, the granites come into contact with the metassediments and a swarm of aplitic dikes crops out with a general NW-SE direction. Dispersed throughout the basin, a large number of quartz veins may also be observed, striking to variable directions (Figure 2). The dominant aquifer systems are mostly of the fractured rock type, although the alluvial deposits may comprise important porous media aquifers in the Campeã valley, given their extension, thickness and permeability (Pacheco and Alencoão 2006).

The most representative soil types are the leptosols, but in association with the main streams, especially in the central area, some spots of fluvisols have also been formed. In the eastern limit of the basin, some anthrosols have developed (Figure 3; Agroconsultores and Coba 1991). In the margins of streams where relief is gentle and soils are richer, land uses are characterised by annual crop agriculture or natural pastures. In the steep hillsides of the western side and at the most elevated altitudes, where the soils are poorer, soil occupation is mostly characterised by pine, eucalyptus or mixed forests and shrub land. Finally, in the 
ms_Text_final version

26 December 2014

areas covered by anthrosols, the land is occupied by vineyards and olive yards. Figure 4

illustrates how land uses were allocated in 2007. The main sources of pollution are agriculture, due to application of farmyard manures and commercial fertilizers on land, and domestic effluents where sewage systems are absent or inoperative. The most common impact of agriculture on groundwater quality is the increase of sulphate and nitrate concentrations.

The management of water resources within the River Sordo basin, especially the protection of groundwater quality, is crucial for the Vila Real municipality, because the public supply of drinking water to this town of 50000 inhabitants is sourced from a dam lake built in the mouth area of the basin in 1990-1997. The concerns about groundwater quality management started in 2001 with the development of a scientific project (Alencoão et al. 2003) for producing an intrinsic vulnerability map of the basin based on the DRASTIC model. Subsequent work involved the evaluation of contamination risk by integration of DRASTIC results with nitrate concentrations, and the reevaluation of DRASTIC factors and their weights using Correspondence Analysis (Pacheco and Sanches Fernandes 2013).

\section{MATERIAL AND METHODS}

\subsection{Digital Database and Computational Tools}

The digital data pertaining to drainage network and topographic contours of River Sordo basin cover sheets $n^{\circ} 101$ and 114 of the Portuguese Topographic Map at the 1:25 000 scale, being available at http://www.igeoe.pt. Based on the topographic contours, a Digital Elevation Model was calculated, from which a terrain slope map was produced (Figure 1) following the Embrapa (1999) classes (Table 1). The soil map (Figure 3) is based on the Agroconsultores and Coba (1991) cartography, being available at http://scrif.igeo.pt. The 
2007 land use map (Figure 4) is based on the 1:100 000 scale Corine Land Cover 2007 map (CLC2007) produced by the Geographic Institute of Portugal (http://www.igeo.pt) for mainland Portugal. Groundwater quality parameters were evaluated at 31 points distributed throughout the basin, corresponding to spring sites (Figure 5). The collection of spring water samples and the execution of chemical analyses were done by Alencoão et al. (2003). The concomitant results, compiled in that report and summarized in the Appendix A. The drainage network, topographic contours and soil map, as well as the spring site locations, were originally referenced to the planimetric datum Lisboa Hayford Gauss with the Universal Transverse Mercator (UTM) projection. The geographic coordinate system of CLC2007 is International 1924 with UTM projection. All maps generated for this study were re-projected so they are referred to a single coordinate system: the UTM projection, Zone 29, with the planimetric datum WGS84 (World Geodetic System 1984), equivalent to the SIRGAS2000 (Geocentric Reference System for the Americas).

All the computational modelling of the spatial data was executed by the IDRISI Selva software (Eastman 2012), developed by the Clark Labs researchers working at the Geography Department of the Clark University (http://www.clarklabs.org). Some maps were drawn using the ArcGIS/ArcMap software developed by ESRI (2010). Apart from ordinary GIS toolsets that allow for analysis, processing and combination of terrain data, the IDRISI Selva software incorporates a set of modules dedicated to the process of decision making, namely algorithms for multi-criteria analysis and weighted linear combination. Since their recent massification, GIS tools became essential in studies with a strong geographic component, and have been used in many environmental projects focused on a diversity of issues: the prevention of groundwater contamination (Pacheco et al. 2015), the assessment of land use conflicts and the evaluation of their impacts on soil erosion, groundwater quality and riverine ecosystems (Pacheco et al. 2014; Valle Junior et al. 2015), 
the prediction of climate change and human related impacts on the hydrology of river catchments and the survival of endangered aquatic species (Santos et al. 2014), the uncovering of natural and anthropogenic sources to groundwater composition (Pacheco and Van der Weijden 2012a,b, 2014a,b; Pacheco et al. 2013), and the modeling of flow and solute transport in aquifers (Pacheco 2013, 2015; Pacheco and Landim, 2005).

\subsection{Flowchart}

A flowchart describing the combined use of a reference method and a monitoring method for the elaboration and updating of aquifer vulnerability maps is illustrated in Figure 6. In a first stage, hydrogeologic, geomorphologic and soil characteristics are combined with land uses in the study area to set up intrinsic and specific vulnerabilities for the local aquifer, respectively. In a second stage, a group of groundwater quality parameters is selected to produce an analogue representation of the overall (intrinsic plus specific) aquifer vulnerability. In case the vulnerability maps generated by Stages 1 and 2 are alike, final vulnerability maps (reference plus analogue) are generated to be used, for example, as tools in groundwater quality protection programs. Otherwise, other groundwater quality parameters have to be selected and Stage 2 is repeated. The final vulnerability maps are valid until changes in land use resulting from political decisions or social and economic development take place that modify significantly the specific vulnerability of the aquifer. These changes can be reported to water managers through updated versions of land use maps, and eventual impacts to groundwater quality resulting therefrom can be detected in monitoring campaigns of the physicochemical parameters. In case the impacts are negligible the vulnerability maps in use need no change. Otherwise, a new map based on the reference method is generated (return to Stage 1) followed by the production of a new analogue map based on the monitoring method (return to Stage 2). In the context of a groundwater quality protection program, the original or updated versions of the 
ms_Text_final version

26 December 2014

vulnerability maps will be used to evaluate the potential risk of groundwater contamination and to propose mitigation measures in case the risk is high, after discussion of these subjects with stakeholders that include politicians, entrepreneurs, opinion makers, general public.

\subsection{The Reference Method}

The reference method is the DRASTIC. The developers of DRASTIC model (Aller et al. 1987) were a committee of the United States Environmental Protection Agency (EPA) and the model calculates an intrinsic vulnerability index based on a weighted addition of seven factors forming the DRASTIC acronym:

DRASTIC $=\sum_{j=1}^{p} w_{j} X_{j}$

where $X$ represents a factor and $w$ a weight. The number of factors $(p)$ is seven, representing the depth to groundwater level $\left(X_{1}=\mathrm{D}\right)$, net recharge rate $\left(X_{2}=\mathrm{R}\right)$, aquifer media $\left(X_{3}=\mathrm{A}\right)$, soil media $\left(X_{4}=\mathrm{S}\right)$, topographic slope $\left(X_{5}=\mathrm{T}\right)$, impact of the vadose zone $\left(X_{6}=\mathrm{I}\right)$, and hydraulic conductivity of the aquifer $\left(X_{7}=\mathrm{C}\right)$. Factor weights are constant values assuming the values $w_{1}=5, w_{2}=4, w_{3}=3, w_{4}=2, w_{5}=1, w_{6}=5, w_{7}=3$. Adjustments to the DRASTIC model were performed by numerous authors, some of whom included land use in the analysis $\left(X_{8}=\mathrm{L}\right)$, with a weight of $4\left(w_{8}=4\right)$, to measure the specific vulnerability of the aquifer (Antonakos and Lambrakis 2007; Pacheco and Sanches Fernandes 2013).

Further details on the original or adapted versions of the DRASTIC model are beyond the scope of this paper and can be found in the above mentioned publications or elsewhere.

\subsection{The Monitoring Method}

The method proposed in Figure 6 to be adopted as monitoring method is the Multi Criteria Analysis (MCA), applied to a group of groundwater quality parameters. 


\subsubsection{Groundwater Quality Parameters}

The Portuguese Decree-Law no 236/98, officially published in 1 August 1998, established the rules, criteria and objectives of water quality with the main purpose of protecting the aquatic media and improving the quality of surface and ground waters as a function of their main uses: human consumption, aquatic life support, bathing and irrigation. In complement to this law, the Portuguese Water Institute (INAG) proposed a scheme for the classification of water quality based on a number of physical and chemical parameters, to be used as technical support in political decisions concerning the protection of demanding ecosystems (OECD 2001). Some of these parameters can be related to the contamination of water by agricultural activities, namely in the course of an excessive application of commercial fertilizers on farm lands, which also corresponds to the main source of groundwater contamination in the study area (River Sordo basin). Being a standard in the evaluation of water quality in Portugal, the INAG classification scheme and parameters (Table 2a) will be incorporated into MCA.

\subsubsection{Multi Criteria Analysis}

According to Malczewski (1999), any multi criteria analysis is a three step procedure involving (1) the selection of factors and restrictions with subsequent elaboration of pixel based (raster) maps describing their spatial distribution, (2) the allocation of a weight to each factor, and (3) the combination of weighted factors and restrictions forming a final MCA map.

\section{Selection of factors and restrictions}

Factors are variables that exhibit values on a continuous scale. In this study, they are represented by the eight groundwater quality parameters listed in Table 2a. Prior to the use in MCA, these values are standardised according to predefined transformation functions 
based on fuzzy logic, called fuzzy pertinence functions. The transformed values of the factors are termed sub-indices and vary between 0 (higher vulnerability) and 1 (lower vulnerability). The correspondence between factor values and sub-indices is depicted in Table $2 \mathrm{~b}$ and has been calculated as follows: $(a)$ the upper limit of quality classes A, B, C and D in Table 2a (e.g. $10 \mathrm{mg} / \mathrm{L}$ in the case of upper class B limit of factor sulphate) were attributed the sub-indices $0.9,0.7,0.5$ and 0.3 , respectively; $(b)$ these upper limit and subindex values were projected on a scatter plot upper limit versus sub-index, the procedure being repeated for each factor; $(c)$ a trend line was fitted to the scatter points, being represented by a polynomial function (column 3 of Table 2b); (d) factor values corresponding to sub-indices in the interval 0.1 to 1 , with step 0.1 , were estimated using the polynomial functions (columns 4-13 of Table 2b). Restrictions discriminate areas that should or not be evaluated for vulnerability, through the elaboration of Boolean raster maps filled with discrete values of 0 (suited for evaluation) or 1 (not suited). The surface water lines of River Sordo basin were classified as not suited because they frequently correspond to discharge areas of the fractured aquifer and therefore are inherently classified as fragile areas (sub-index $=0$ in every factor). Abbaspour et al. (2011) adopted factors, restrictions and transformation functions similar to those used in this study.

\section{Weighting of factors}

The next step towards the evaluation of aquifer vulnerability using MCA is the weighting of factors. The adopted technique is known as Analytic Hierarchy Process and was developed by Saaty (1980), being recently incorporated into the IDRISI Selva software as WEIGHT module (Eastman 2012). Firstly, factor names are used as row and column heads

of a square matrix (Table 3). Secondly, factors are compared in a pair-wise mode regarding their relative importance in the evaluation of aquifer vulnerability. The comparison is quantified using a number between 1/9 (extremely less important) and 9 (extremely more 
important). This number $(n)$ will populate the lower triangle below the main diagonal of the square matrix while its reciprocal $(1 / n)$ will populate the upper triangle. Table 3 depicts the choices of $n$ and $1 / n$ as regards the present case study. Thirdly, the main eigenvector of the square matrix is calculated, the components of which are final weights of the factors (last column of Table 3). Finally, a statistical index is calculated, to check whether the factor weights are consistent. This so-called consistency ratio (CR), which ranges from 0 to 1 , measures the probability of matrix values to be generated in a random manner. As reported in Saaty (1980), when this probability becomes greater than $10 \%(C R \geq 0.1)$ the choices of $n$ and $1 / n$ are not truthful and hence must be reassessed.

\section{Evaluation of aquifer vulnerability}

In a final step, aquifer vulnerability is calculated by Weighted Linear Combination as implemented by the WLC module of IDRISI Selva software (Eastman 2012). In a run of this module, maps of factors (e.g. pH, nitrate, etc.) are produced for the study area by interpolation of factor values measured at the monitoring points (e.g. Figure 5).

Subsequently, these maps are joined with tables that set up correspondences between factor values and sub-indices (Table $2 \mathrm{~b}$ ) to produce maps of standardized factors ( $X_{i}$ maps, where $i$ represents a factor). Additionally, the drainage network map is used to draw a restriction map ( $Y_{j}$ map, where $j$ is the restriction), whereby pixels closer than ten meters to a water course or a lake are assigned a score of 0 and the remaining pixels a score of 1 . Finally, the aquifer vulnerability map ( $S$ map) is calculated by the equation:

$S=\sum_{i=1}^{p} w_{i} X_{i} \prod_{j=1}^{q} Y_{j}$, for every pixel in the map

where $w_{i}$ is the weight of factor $i$ as calculated by the WEIGHT module described in the previous section, $p$ is the number of factors ( 8 for the present case study) and $q$ the number 
ms_Text_final version

26 December 2014

of restrictions ( 1 for the present case study). At the end, $S$ values are reclassified into four vulnerability classes, from invulnerable to extremely vulnerable, according to Table 4.

\subsection{Interaction between the Reference and Monitoring Methods}

For the sake of comparison between the results of DRASTIC (reference method) and MCA (monitoring method), vulnerability classes of DRASTIC (Aller et al. 1987) are reclassified in the interval $0-1$, according to Table 5 , and subsequently a matrix is calculated by crosstabulation of the reclassified DRASTIC and the MCA results. Based on the results of this cross tabulation, a decision is made about the reliability of using DRASTIC and MCA as analogue models.

\section{RESULTS AND DISCUSSION}

\subsection{Results}

The DRASTIC map of River Sordo basin is reported in Pacheco and Sanches Fernandes (2013) and resulted from application of this method to a variety of hydrogeological, geomorphologic and soil data, being illustrated in Figure 7. This figure is now reproduced for the sake of comparison with the map generated by application of MCA to the groundwater quality data listed in the Appendix A. The DRASTIC map portrays intrinsic vulnerability in the basin as a background of low vulnerability areas $(100<$ DRASTIC $<$ 119; class 3 of Table 5), marked by the hard rock geology. These areas are, however, interrupted by spots where vulnerability is moderate $(120<$ DRASTIC $<139$; class 4$)$ due to the presence of alluvial cover deposits or the contact areas between metassediments and granites (Figure 2), and by spots where vulnerability is very low $(80<$ DRASTIC $<99$; class 2) because hillside slopes are very steep (Figure 1). 
The MCA map is illustrated in Figure 8. The results of Analytic Hierarchy Process reveal a prevalence of electrical conductivity, sulphate and copper as aquifer vulnerability indicators in the River Sordo basin, exhibited in the weights of corresponding factors: $0.2595,0.1930$ and 0.1277 , respectively (last column of Table 3 ). The consistency ratio (CR) was 0.07 , or $7 \%$, which confirms a correct choice for the values above and below the main diagonal of Table 3 that describe the relative importance of the factors in the diagnosis of aquifer vulnerability. According to Figure $8,62.22 \%$ of the basin $\left(30.698 \mathrm{~km}^{2}\right)$ is invulnerable, $36.98 \%\left(18.256 \mathrm{~km}^{2}\right)$ is weakly vulnerable, and $0.79 \%\left(0.401 \mathrm{~km}^{2}\right)$ is vulnerable. Because the higher vulnerability classes (extremely vulnerable and highly vulnerable) are not present in the basin, there is a low potential risk for groundwater contamination within this catchment. Eventually, this is a direct consequence of low land use pressures or conflicts in the studied area (Valle Junior et al. 2014a).

According to Leone et al. (2009), the performance of a target model as measured by a control model is essentially determined by a general correspondence of trends. A comparison between the DRASTIC (assumed as target model) and MCA (assumed as control model) vulnerability maps was accomplished by a cross tabulation of Figure 7 and Figure 8 using the IDRISI Selva software (CROSSTAB tool), the results being given in Table 5. As a complement, the MCA map was cross tabulated with the maps of target model Vector-DRASTIC and control model $\mathrm{NO}_{3}$-DRASTIC reported in Pacheco and Sanches Fernandes (2013), the results being listed in the last two columns of Table 5. The Vector-DRASTIC (Pacheco and Sanches Fernandes 2013) is a modified version of original DRASTIC whereby factors and corresponding weights are adjusted by Correspondence Analysis. For the River Sordo basin, Vector-DRASTIC $=5 \mathrm{~T}+3.3 \mathrm{R}+3 \mathrm{~A}+32$. $\mathrm{The}^{\mathrm{NO}_{3}-}$ DRASTIC (Antonakos and Lambrakis 2007) is another modified version of original DRASTIC which adds up land use to the model and adjusts factor weights according to the 
correlation of factor values with nitrate concentrations in local ground waters. For the River Sordo basin, $\mathrm{NO}_{3}-\mathrm{DRASTIC}=5 \mathrm{D}+\mathrm{R}+2 \mathrm{~A}+3.1 \mathrm{~S}+3.4 \mathrm{~T}+5 \mathrm{I}+3 \mathrm{C}+2 \mathrm{~L}$. The graphical representation of all cross tabulations is illustrated in Figure 9. It is clear that original DRASTIC is more conservative than the modified versions as regards vulnerability evaluation, because the highest frequency class is class 3 in the first case and class 1 in the other cases. The results of MCA seem to set up a bridge between the original and modified DRASTIC models, because the highest frequency class is now represented by class 2 . It should be noted that Vector-DRASTIC was developed with the purpose of identifying and minimizing redundancy between DRASTIC features that increase artificially the original index. The high performance of Vector-DRASTIC in the River Sordo basin is unquestionable given the notable adherence of Vector-DRASTIC results to the actual distribution of groundwater contamination described by the results of $\mathrm{NO}_{3}$-DRASTIC (Figure 9). Following this rationale, it could be argued that a shift of MCA vulnerabilities (maximum frequency in class 2) towards values higher than Vector-DRASTIC counterparts (maximum frequency in class 1) correspond to an overestimation of the former due to redundant correlations eventually existing among the quality parameters. For example, if nitrate and sulphate in local ground waters result from dissolution of different fertilizers, then concentrations of these ions are self determined and hence these quality parameters are independent and suited to be used in MCA. But if they result from dissolution of the same fertilizer, redundant correlations will develop between their concentrations reducing their independency and therefore their suitability to be used in MCA. Despite the slight discrepancy between the results of MCA and DRASTIC, it should be recognised that more than $96 \%$ of the basin, as determined by the target or control models, falls within the invulnerable and weakly vulnerable classes (Tables 4 and 5). This is strong indication that target and control models are comparable, or in other words that the control model can be 
classified as analogue of the target model. Furthermore, the control model, which uses solely groundwater quality data as factors in the aquifer vulnerability evaluation, proves to be simpler and less costly than the target model, which requires the assemblage of hydrogeological, geomorphologic and soil data. Hence, it can be finally stated that MCA is suited for the monitoring of aquifer vulnerability at short time intervals.

\subsection{Discussion}

\subsubsection{Hydrological sustainability}

Sustainability is a manifold concept, approachable from many points of view: hydrological, ecological, economic, social, legal, institutional, inter- or intra-generational, and political (Llamas et al. 2006). It is unlikely that all aspects of sustainability can be achieved at the same point in time. This study is focused on the hydrological perspective of sustainability, namely on the topic of groundwater quality protection. Presently, the vulnerability status of River Sordo basin is low and the risk of groundwater contamination is small. This is a benefit for the region because the basin drains to a lake that is the main resource of drinking water for a community of 50000 people. However, attention must be paid to eventual changes in land use resulting from social or economic development or due to future political decisions. This awareness is critical because the accomplishment of a local hydrological sustainability through the establishment of a monitoring programme concerning aquifer vulnerability levels across the target area will be successful solely if the environmental dimension discussed in the present paper is accompanied by the social, economic and political dimensions that were incorporated in Figure 6 but not addressed. This includes stakeholder participation for the social dimension, regulatory interventions for the economic dimension, and governmental and institutional responsibilities for the political dimension. These dimensions have been integrated in sustainability studies carried out by other research groups (e.g. Pandey et al. 2011). A successful articulation of all these 
ms_Text_final version

26 December 2014

dimensions requires a significant degree of trust among the stakeholders, which can be strengthened by the generation of data, information and knowledge and their dissemination in a transparent way (Llamas et al. 2006).

\subsubsection{Water Framework Directive}

A significant and innovative political decision concerning hydrological sustainability in the European Union was the approval of a Water Framework Directive (WFD), coined as Directive $n^{\circ}$ 2000/60/EC, which aimed at achieving a good ecological status of surface water bodies by 2015 . This directive was transposed to the Portuguese legislation through the publication of a Water Law, in 29 of December 2005, called Law $n^{\circ} 56 / 2005$. In both cases, the pathway towards hydrological sustainability is based on the determination of quality objectives, the monitoring of water bodies, the definition of intervention measures, and the control of pressure sources. In order to apply the WFD correctly, it is necessary to define the water quality status and then to improve water quality in order to reach the good status. Therefore, what is fundamental is a deep and detailed knowledge of the present environmental framework affecting the water body, both in terms of water quality and of anthropogenic pressures (Mirauda and Ostoich 2011). The results obtained for the River Sordo basin show that the coupling of DRASTIC with MCA is a correct implementation of the WFD and Law n ${ }^{\circ} 56 / 2005$ at the scale of a small watershed. They also reveal the good status of River Sordo ground waters, as regards quality parameters related to contamination by agricultural activities.

The quality of River Sordo lake water is not accounted for by the DRASTIC or MCA models and therefore was not addressed in this study. However, Pacheco and Sanches Fernandes (2013) reported that nitrate concentrations in this lake follow an oscillating drift with minimum and maximum scores around 2 and $5 \mathrm{mg} / \mathrm{L}$. This trend is interrupted by a few higher values, however not exceeding $15 \mathrm{mg} / \mathrm{L}$ and falling below the recommended (25 
$\mathrm{mg} / \mathrm{L})$ or allowed $(50 \mathrm{mg} / \mathrm{L})$ limits imposed by the Portuguese Decree-Law n ${ }^{\circ}$ 236/98. The authors argued that fluctuations are most probably related with a periodical input of atmospheric gases and aerosols by washout of combined nitrogen $\left(\mathrm{NO}_{\mathrm{x}}, \mathrm{NH}_{3}, \mathrm{NH}_{4}{ }^{+}\right)$. They further noted that exceptions confirm events of excess fertilization in farmyards located upstream of the lake that can sporadically raise nitrate concentrations above the background fluctuation. Pacheco and Sanches Fernandes (2013) finally concluded that nitrate migration across the basin has a limited impact on the quality of Sordo lake water. In this study, the impact analysis is supported by more information concerning the lake water, namely data on the quality parameters used in MCA (Table 2b). These data were assembled from the Portuguese Water Institute (http://snirh.pt) for the period 2000-2010. The purpose was to calculate an overall sub-index value based on the transformation functions listed in Table $2 \mathrm{~b}$ and the factor weights given in Table 3 , and to associate a concomitant quality class to the lake water in each year. The results are illustrated in Figure 10 and confirm a rewarding status for the River Sordo lake water, which is essentially ranked as very good (class B of Table 2a) with just a few exceptions where the grade dropped to good (class C).

While the River Sordo basin seems to have an intrinsic self defense ability, which allows Sordo lake water to remain uncontaminated even in the presence of relevant potential threats (26.8\% of areas used for agriculture), events of excess fertilizing should nevertheless be prevented. In this context, some general recommendations are pertinent in regard to agriculture management practices for water quality protection, as part of an overall watershed approach. This would involve, for example, work sessions with farmers addressing methods for reducing non-point sources of pollution from croplands, namely through integrated use of conservation tillage, crop nutrient management, conservation buffers, irrigation water management, grazing management, animal feeding operations management. Besides, in order to implement the Law $n^{0} 56 / 2005$ correctly, some other 
measures are due, concerning the protection of water resources around drilled wells and recharge areas. In regard to boreholes used for public supply of drinking water, protection is promoted by the delineation of protection zones (immediate, intermediate and extended) around those boreholes, where most economic activities are forbidden or conditioned. The protection of groundwater resources within aquifer recharge areas requires the prior delineation of those areas. In the River Sordo basin, Pacheco and Van der Weijden (2013) drew the boundaries of main recharge areas using oxygen isotopes, which correspond to the highlands (see Figure 1 and Figure 7). Inside their boundaries land use should be conditioned, for example by legally imposing special protection zones for aquifer recharge where only some economic activities could be licensed.

\subsubsection{Land use planning}

Land use alterations whose objectives are usually based upon short sighted economic benefit to owners, give little concern to integration with the regional landscape. The euphemistic term "development", applied to land use alteration, has largely taken the pragmatic form of engineering for short term economic objectives, losing sight of longer term perspectives on environmental sustainability. The results are an unbalance situation, which leads to adverse effects on soils as well as on the quantity and quality of water resources (Collin and Melloul 2003). In the River Sordo basin, the combination of a multi criteria analysis of soil vulnerability with an evaluation of environmental land use conflicts showed that soils are at effective risk of degradation in approximately $10.4 \%$ of the area. And the main cause for the potential degradation of the soil was found to be the invasion of steep slope hillsides by irrigated crop lands, vineyards and olive yards (Valle Junior et al. 2014a). This unbalance situation is also found to be the cause of ground water contamination around those crop lands (Valle Junior et al. 2014b). A solution to the problem could be a progressive return of conflict areas to a balanced situation. This would 
require the elimination of land use conflicts by readapting the target areas to the so-called natural land uses, set up on the basis soil suitability, i.e. on the comparison between the soil characteristics (temperature regime, rooting conditions, fertility, toxicity, drainage, water availability, erosion risk, presence of obstacles) and the requisites or limitations of a particular land use.

\section{CONCLUSIONS}

The simultaneous production of DRASTIC (defined as reference) and MCA (defined as monitoring or analogue) maps was found to be crucial for the incorporation of aquifer vulnerability information in the agenda of groundwater quality protection programs, given the robustness of DRASTIC results and the flexibility and ease of application of MCA. The study area was the River Sordo basin, a mountainous catchment located in northeast Portugal, shaped on crystalline rocks and where land uses are mostly dominated by forests

in the highlands and low intensity agriculture in the low altitude valleys. With exception of a small area $(\approx 10 \%)$, actual land uses are in a balanced situation with natural land uses defined on the basis of a soil suitability assessment. For that reason, the basin is essentially invulnerable or at the most weakly vulnerable to groundwater contamination. The limited coverage by areas with land use conflicts is also the reason appointed for the good quality status attained by the local ground and dam lake waters, a very good news for the 50000 inhabitants of Vila Real, the local municipality, who drink water from the dam lake. The very good status of Sordo lake water is reported to occur in the period 2000-2010, even before the deadline imposed by the Water Framework Directive of the European Parliament and Council, coined as Directive $\mathrm{n}^{\mathrm{o}} 2000 / 60 / \mathrm{EC}$, which aimed at achieving a good status of surface water bodies by 2015 . The overall conclusion on the present case study seems to be 
ms_Text_final version

that conformity between actual and natural land uses is a fundamental milestone towards the achievement of hydrological sustainability in small watersheds.

\section{ACKNOWLEDGEMENTS}

The authors would like to thank the Coordination of Improvement of Higher Education Personnel (CAPES) for the scholarship Process $n^{\circ} 10297 / 12-0$, to the University of Trás-osMontes and Alto Douro (UTAD) and the Center for the Research and Technology of AgroEnvironmental and Biological Sciences (CITAB) for technical support, and to the Federal Institute of Triângulo Mineiro (IFTM) for the support of a sabbatical year in Portugal. As regards the corresponding author, the research was funded by national funds (FCT Portuguese Foundation for Science and Technology) under the strategic project of the Vila Real Chemistry Research Center (PEst-OE/QUI/UI0616/2014). As regards the other authors, the research was supported by European Union funds (FEDER/COMPETE Operational Competitiveness Programme) and by national funds (FCT - Portuguese Foundation for Science and Technology) under the project FCOMP-01-0124-FEDER022692 . 


\section{REFERENCES}

Abbaspour M, Mahin AS, Arjmandy R, Naimi, B (2011) Integrated approach for land use suitability analysis. International Agrophysics 25:311-318.

Agroconsultores Ltd, Coba Ltd (1991) Carta de solos, carta do uso atual da terra e carta de aptidão da terra do nordeste de Portugal. Universidade de Trás-os-Montes e Alto Douro. Projecto de desenvolvimento rural integrado de Trás-os-Montes e Alto Douro (PDRITM).

Alencoão AMP, Sousa Oliveira A, Pacheco FAL (2003) Final Report, project POCTIICTA/40772/2001 "Physical and Chemical Hydrogeology - Modeling Crystalline Massifs and Porous Media". Portuguese Science and Technology Foundation, 134p.

Aller L, Bennet T, Lehr JH, Petty RJ (1987) DRASTIC: a standardized system for evaluating groundwater pollution potential using hydrogeologic settings. US EPA document no. EPA/600/285-018.

Antonakos AK, Lambrakis NL (2007) Development and testing of three hybrid methods for assessment of aquifer vulnerability to nitrates, based on the DRASTIC model, an example from NE Korinthia, Greece. Journal of Hydrology 333(2-4):288-304.

Chowdhury RK, Rahman R (2008) Multicriteria decision analysis in water resources management: the malnichara channel improvement. International Journal of Environmental Science and Technology 5(2):195-204.

Collin ML, Melloul AJ (2003) Assessing groundwater vulnerability to pollution to promote sustainable urban and rural development. Journal of Cleaner Production 11:727-736.

Dou C, Wolt W, Bogardi I (1999) Fuzzy rule-based approach to describe solute transport in the unsaturated zone. Journal of Hydrology 220(1-2):74-85.

ESRI (2010) ArcGISArcMap (version 10). New York St., Redlands, USA.

Eastman JR (2012) IDRISI Selva Manual. Worcester, MA: Clark Labs, Clark University. 322p. Provided as a PDF with the IDRISI Selva software package.

Embrapa (1999) Empresa Brasileira de Pesquisa Agropecuária. Centro Nacional de Pesquisa de Solos. Sistema brasileiro de classificação de solos. Rio de Janeiro. 412 p.

Focazio MJ, Reilly TE, Rupert MG, Helsel DR (2005) Assessing groundwater vulnerability to contamination: providing scientifically defensible information for decision makers. US Geological Survey Circular 1224.

Garfi M, Ferrer-Martí L, Onoli A, Tondelli S (2011) Multi-criteria analysis for improving strategic environmental assessment of water programmes: a case study in semi-arid region of Brazil. Journal of Environmental Management 92:665-675. 
Huan H, Wang J, Teng Y (2012) Assessment and validation of groundwater vulnerability to nitrate based on a modified DRASTIC model: a case study in Jilin City of northeast China. Science of the Total Environment 440:14-23.

Javadi S, Kavehkar N, Mousavizadeh MH, Mohammadi K (2011a) Modification of DRASTIC Model to Map Groundwater Vulnerability to Pollution Using Nitrate Measurements in Agricultural Areas. Journal of Agricultural Science and Technology 13:239-249.

Javadi S, Kavehkar N, Mohammadi K, Khodadadi A, Kahawita R (2011b) Calibrating DRASTIC using field measurements, sensitivity analysis and statistical methods to assess groundwater vulnerability. Water International 36(6):719-732.

Jiang HE, Eastman JR (2000) Application of fuzzy measures in multi-criteria evaluation in GIS. International Journal of Geographical Information Systems 14(2):173-184.

Llamas MR, Martinez-Santos P, de la Hera A (2006) The manifold dimensions of groundwater sustainability: an overview. In: Ragone S, de la Hera A, Hernandez-Mora N (eds.), Proceedings of the International Symposium on Groundwater Sustainability. National Ground Water Association Press, OH, USA.

Leone A, Ripa MN, Uricchio V, Deák I, Vargay Z. (2009) Vulnerability and risk evaluation of agricultural nitrogen pollution for Hungary's main aquifer using DRASTIC and GLEAMS models. Journal of Environmental Management 90(10):2969-2978.

Malczewski J (1999) GIS and Multicriteria Decision Analysis. John Wiley and Sons, New York, $392 \mathrm{p}$.

Masetti M, Sterlacchini S, Ballabio C, Sorichetta A, Poli S (2009) Influence of threshold value in the use of statistical methods for groundwater vulnerability assessment. Science of the Total Environment 407:3836-3846.

Mirauda D, Ostoich M (2011) Surface water vulnerability assessment applying the integrity model as a decision support system for quality improvement. Environmental Impact Assessment Review 31:161-171.

Neshat A, Pradhan B, Dadras M (2014) Groundwater vulnerability assessment using an improved DRASTIC method in GIS. Resources, Conservation and Recycling 86:74-86.

Neukum C, Azzam R. (2009) Quantitative assessment of intrinsic groundwater vulnerability to contamination using numerical simulations. Science of the Total Environment 408:245-254.

OECD (2001) Environmental Performance Reviews: Portugal. OECD, 216p.

Pacheco FAL (2013) Hydraulic diffusivity and macrodispersivity calculations imbedded in a geographic information system. Hydrological Sciences Journal 58(4):930-944.

Pacheco FAL (2015) Regional groundwater flow in hard rocks. Science of the Total Environment 506-507:182-195. 
Pacheco FAL, Alencoão AMP (2006) Role of fractures in weathering of solid rocks: narrowing the gap between experimental and natural weathering rates. Journal of Hydrology 316:248-265.

Pacheco FAL, Landim PMB (2005) Two-way regionalized classification of multivariate data sets and its application to the assessment of hydrodynamic dispersion. Mathematical Geology 37(4):393-417.

Pacheco FAL, Sanches Fernandes LFS (2013) The multivariate statistical structure of DRASTIC model. Journal of Hydrology 476:442-459.

Pacheco FAL, Van der Weijden CH (2012a) Weathering of plagioclase across variable flow and solute transport regimes. Journal of Hydrology 420-421: 46-58.

Pacheco FAL, Van der Weijden CH (2012b) Integrating Topography, Hydrology and Rock

Structure in Weathering Rate Models of Spring Watersheds. Journal of Hydrology 428-429: 32-50.

Pacheco FAL, Van der Weijden CH (2014a) Role of hydraulic diffusivity in the decrease of weathering rates over time. Journal of Hydrology 512: 87-106.

Pacheco FAL, Van der Weijden CH (2014b) Modeling rock weathering in small watersheds. Journal of Hydrology 513:13-27.

Pacheco FAL, Landim PMB, Szocs T (2013) Anthropogenic impacts on mineral weathering: a statistical perspective. Applied Geochemistry 36:34-48.

Pacheco FAL, Pires LMGR, Santos RMB, Sanches Fernandes LF (2015) Factor weighting in DRASTIC modeling. Science of the Total Environment 505: 474-486.

Pacheco FAL, Varandas SGP, Sanches Fernandes LF, Valle Junior RF (2014) Soil losses in rural watersheds with environmental land use conflicts. Science of the Total Environment 485-486C: $110-120$.

Panagopoulos GP, Antonakos AK, Lambrakis NJ (2006) Optimization of the DRASTIC method for groundwater vulnerability assessment via the use of simple statistical methods and GIS.

Hydrogeology Journal 14: 894-911.

Pandey VP, Shrestha S, Chapagain SK, Kazama F (2011) A framework for measuring groundwater sustainability. Environmental Science \& Policy 14:396-407.

Rezaei F, Safavi HR, Ahmadi A (2013) Groundwater vulnerability assessment using fuzzy logic: A Case Study in the Zayandehrood aquifers, Iran. Environmental Management 51:267-277.

Saaty TL (1980) The Analytic Hierarchy Process. Planning, Priority Setting, Resource Allocation. Mc Graw-Hill, USA.

Santos RMB, Sanches Fernandes LF, Moura JP, Pereira MG, Pacheco FAL (2014) The impact of climate change, human interference, scale and modeling uncertainties on the estimation of aquifer properties and river flow components. Journal of Hydrology 519:1297-1314. 
Sorichetta A, Masetti M, Ballabio C, Sterlacchini S, Beretta GP (2011) Reliability of groundwater vulnerability maps obtained through statistical methods. Journal of Environmental Management 92:1215-1224.

Valle Junior RF, Varandas SGP, Sanches Fernandes LF, Pacheco FAL (2014a) Environmental land use conflicts: a threat to soil conservation. Land use Policy 41:172-185.

Valle Junior RF, Varandas SGP, Sanches Fernandes LF, Pacheco FAL (2014b) Impact of land use conflicts on groundwater quality. Groundwater quality in rural watersheds with environmental land use conflicts. Science of the Total Environment 493:812-827.

Valle Junior RF, Varandas SGP, Pacheco FAL, Pereira VR, Santos CF, Cortes RMV, Fernandes LFS (2015) Impacts of land use conflicts on riverine ecosystems. Land Use Policy 43:48-62.

Wang J, He J, Chen H (2012) Assessment of groundwater contamination risk using hazard quantification, a modified DRASTIC model and groundwater value, Beijing Plain, China. Science of the Total Environment 432:216-226.

Yu C, Yao Y, Hayes G, Zhang B, Zheng C (2010) Quantitative assessment of groundwater vulnerability using index system and transport simulation, Huangshuihe catchment, China. Science of the Total Environment 408:6108-6116. 
ms_Text_final version

TABLE 1 - Slope intervals and associated reliefs (Embrapa 1999).

\begin{tabular}{ll}
\hline Slope class (\%) & \multicolumn{1}{c}{ Relief description } \\
\hline $0-5$ & Flat to smoothly undulated \\
$5-10$ & Smoothly undulated to undulated \\
$10-20$ & Undulated to considerably undulated \\
$20-47$ & Considerably undulated to strongly undulated \\
$>47$ & Strongly undulated to mountainous \\
\hline
\end{tabular}

TABLE 2a - Classification scheme for water quality proposed by the Portuguese Water Institute (OECD 2000), concerning some parameters that can be associated with contamination by agriculture. The quality classes are: $\mathrm{A}$ (excellent); $\mathrm{B}$ (very good); $\mathrm{C}$ (fair); $\mathrm{D}$ (poor); $\mathrm{E}$ (very poor). Symbols: $\mathrm{NO}_{3}{ }^{-}$(nitrate); $\mathrm{Fe}$ (iron); $\mathrm{Mn}$ (manganese); $\mathrm{Zn}$ (zinc); $\mathrm{Cu}$ (copper); $\mathrm{SO}_{4}{ }^{2-}$ (sulphate); Ec(electrical conductivity).

\begin{tabular}{ccccccc}
\hline \multirow{2}{*}{ Parameter } & Unit & \multicolumn{5}{c}{ Quality class } \\
\cline { 3 - 7 } & & $\mathrm{A}$ & $\mathrm{B}$ & $\mathrm{C}$ & $\mathrm{D}$ & $\mathrm{E}$ \\
\hline $\mathrm{nH}$ & & $6.5-8.5$ & $5.5-9.0$ & $5-10$ & $4.5-11$ & $\mathrm{nd}$ \\
$\mathrm{NO}_{3}{ }^{-}$ & $\mathrm{mg} \mathrm{NO}{ }_{3} / \mathrm{L}$ & $\leq 5.0$ & $5.1-25$ & $25.1-50$ & $50.1-80$ & $>80$ \\
$\mathrm{Fe}$ & $\mathrm{mg} / \mathrm{L}$ & $\leq 0.50$ & $0.51-1.00$ & $1.01-1.50$ & $1.51-2.00$ & $>2.00$ \\
$\mathrm{Mn}$ & $\mathrm{mg} / \mathrm{L}$ & $\leq 0.10$ & $0.11-0.25$ & $0.26-0.50$ & $0.51-1.00$ & $>1.00$ \\
$\mathrm{Zn}$ & $\mathrm{mg} / \mathrm{L}$ & $\leq 0.30$ & $0.31-1.00$ & $1.01-3.00$ & $3.01-5.00$ & $>5.00$ \\
$\mathrm{Cu}$ & $\mathrm{mg} / \mathrm{L}$ & $\leq 0.050$ & $0.051-0.20$ & $0.201-0.50$ & $0.501-1.00$ & $>1.00$ \\
$\mathrm{SO}_{4}{ }^{2-}$ & $\mathrm{mg} \mathrm{SO} / \mathrm{L}$ & $\leq 5$ & $5-10$ & $10-20$ & $20-25$ & $>25$ \\
$\mathrm{Ec}$ & $\mu \mathrm{S} / \mathrm{cm}$ & $\leq 750$ & $751-1000$ & $1001-1500$ & $1501-3000$ & $>3000$ \\
\hline
\end{tabular}


TABLE $2 \mathrm{~b}$. Factors and transformation functions used in MCA. Correspondence between water quality classes (Table 2a), associated factor values and corresponding sub-indices (i). Symbols: LL and UL - lower limit and upper limit; for other symbols see Table 2a.

\begin{tabular}{|c|c|c|c|c|c|c|c|c|c|c|c|c|}
\hline \multirow{4}{*}{ Factor } & \multirow{4}{*}{ Unit } & \multirow{4}{*}{$\begin{array}{l}\text { Transformation } \\
\text { function }\end{array}$} & \multicolumn{10}{|c|}{ Quality class } \\
\hline & & & \multicolumn{2}{|c|}{$E$} & \multicolumn{2}{|c|}{$\mathrm{D}$} & \multicolumn{2}{|c|}{$\mathrm{C}$} & \multicolumn{2}{|c|}{$B$} & \multicolumn{2}{|c|}{ A } \\
\hline & & & 0.1 & 0.2 & 0.3 & 0.4 & 0.5 & 0.6 & 0.7 & 0.8 & 0.9 & 1 \\
\hline & & & \multicolumn{10}{|c|}{ Factor value } \\
\hline$\overline{\mathrm{pH}(\mathrm{LL})}$ & & $12.83-7.22 i+2.29 i^{2}$ & $\geq 12.13$ & 11.48 & 10.87 & 10.31 & 9.79 & 9.32 & 8.90 & 8.52 & 8.19 & $<7.90$ \\
\hline $\mathrm{pH}(\mathrm{UL})$ & & $2.67+6.79 i-3.26 i^{2}$ & $\geq 3.32$ & 3.90 & 4.42 & 4.87 & 5.25 & 5.58 & 5.83 & 6.02 & 6.15 & $<6.21$ \\
\hline $\mathrm{NO}_{3}^{-}$ & $\begin{array}{c}\mathrm{mg} \\
\mathrm{NO}_{3} / \mathrm{L}\end{array}$ & $109.2-154.0 \mathrm{i}+43.5 \mathrm{i}^{2}$ & $\geq 94.25$ & 80.15 & 66.92 & 54.57 & 43.08 & 32.46 & 22.72 & 13.84 & 5.84 & 0.00 \\
\hline $\mathrm{Fe}$ & $\mathrm{mg} / \mathrm{L}$ & $2.46--2.17 i$ & $\geq 2.25$ & 2.03 & 1.81 & 1.60 & 1.38 & 1.16 & 0.94 & 0.73 & 0.51 & $<0.29$ \\
\hline $\mathrm{Mn}$ & $\mathrm{mg} / \mathrm{L}$ & $1.44-2.53 i+1.53 i^{2}$ & $\geq 1.21$ & 1.00 & 0.82 & 0.68 & 0.56 & 0.48 & 0.42 & 0.40 & 0.40 & $<0.44$ \\
\hline $\mathrm{Zn}$ & $\mathrm{mg} / \mathrm{L}$ & $7.15-11.73 i+4.51 i^{2}$ & $\geq 6.03$ & 4.99 & 4.04 & 3.19 & 2.42 & 1.74 & 1.16 & 0.66 & 0.26 & 0.00 \\
\hline $\mathrm{Cu}$ & $\mathrm{mg} / \mathrm{L}$ & $1.50-3.19 i+1.94 i^{2}$ & $\geq 1.21$ & 0.94 & 0.72 & 0.54 & 0.40 & 0.29 & 0.23 & 0.20 & 0.21 & $<0.26$ \\
\hline $\mathrm{SO}_{4}{ }^{2-}$ & $\begin{array}{c}\mathrm{mg} \\
\mathrm{SO}_{4} / \mathrm{L}\end{array}$ & $33.1-32.7 i$ & $\geq 29.86$ & 26.58 & 23.30 & 20.02 & 16.74 & 13.46 & 10.19 & 6.91 & 3.63 & $<0.35$ \\
\hline $\mathrm{Ec}$ & $\mu \mathrm{S} / \mathrm{cm}$ & $4244.2-7398.5 i+3825.7 i^{2}$ & $\geq 3542.68$ & 2917.60 & 2369.03 & 1896.98 & 1501.45 & 1182.43 & 939.93 & 773.94 & 684.47 & 671.51 \\
\hline
\end{tabular}


ms_Text_final version

TABLE 3. Results of factor weighting by the Analytic Hierarchy Process (Saaty 1980). For this set of factor weights, the calculated consistency ratio was $C R=0.07$ (7\%). Symbols: see Table $2 b$.

\begin{tabular}{ccccccccccc}
\hline & $\mathrm{pH}(\mathrm{LL})$ & $\mathrm{pH}(\mathrm{UL})$ & $\mathrm{NO}_{3}{ }^{-}$ & $\mathrm{Fe}$ & $\mathrm{Mn}$ & $\mathrm{Zn}$ & $\mathrm{Cu}$ & $\mathrm{SO}_{4}{ }^{2-}$ & $\mathrm{Ec}$ & $\begin{array}{c}\text { Factor } \\
\text { weight }\end{array}$ \\
\hline $\mathrm{pH}(\mathrm{LL})$ & 1 & $1 / 2$ & $1 / 2$ & $1 / 3$ & 1 & $1 / 2$ & $1 / 2$ & $1 / 3$ & $1 / 4$ & 0.0468 \\
$\mathrm{pH}(\mathrm{UL})$ & 2 & 1 & $1 / 2$ & $1 / 2$ & $1 / 3$ & $1 / 3$ & $1 / 3$ & $1 / 2$ & $1 / 3$ & 0.0512 \\
$\mathrm{NO}_{3}{ }^{-}$ & 2 & 2 & 1 & $1 / 2$ & $1 / 2$ & $1 / 2$ & $1 / 2$ & $1 / 4$ & $1 / 3$ & 0.0599 \\
$\mathrm{Fe}$ & 3 & 2 & 2 & 1 & $1 / 2$ & $1 / 2$ & $1 / 2$ & $1 / 3$ & $1 / 4$ & 0.0740 \\
$\mathrm{Mn}$ & 1 & 3 & 2 & 2 & 1 & $1 / 2$ & $1 / 2$ & $1 / 2$ & $1 / 4$ & 0.0872 \\
$\mathrm{Zn}$ & 2 & 3 & 2 & 2 & 2 & 1 & $1 / 3$ & $1 / 3$ & $1 / 3$ & 0.1006 \\
$\mathrm{Cu}$ & 2 & 3 & 2 & 2 & 2 & 3 & 1 & $1 / 3$ & $1 / 4$ & 0.1277 \\
$\mathrm{SO}_{4}{ }^{2-}$ & 3 & 2 & 4 & 3 & 2 & 3 & 3 & 1 & $1 / 2$ & 0.1930 \\
$\mathrm{Ec}$ & 4 & 3 & 3 & 4 & 3 & 3 & 4 & 2 & 1 & 0.2595 \\
\hline
\end{tabular}

TABLE 4. MCA aquifer vulnerability classes, associated descriptions and standardised score intervals.

\begin{tabular}{ccc}
\hline Vulnerability class & Description & Standardised score interval \\
\hline 5 & Extremely vulnerable & $0.000-0.196$ \\
4 & Strongly vulnerable & $0.196-0.392$ \\
3 & Vulnerable & $0.392-0.588$ \\
2 & Weakly vulnerable & $0.588-0.784$ \\
1 & Invulnerable & $0.784-0.980$ \\
\hline
\end{tabular}


ms_Text_final version

TABLE 5. DRASTIC aquifer vulnerability classes, associated descriptions and conventional and standardised score intervals.

\begin{tabular}{cccc}
\hline $\begin{array}{c}\text { Vulnerability } \\
\text { class }\end{array}$ & Description & $\begin{array}{c}\text { Conventional score } \\
\text { interval }\end{array}$ & $\begin{array}{c}\text { Standardised score } \\
\text { interval }\end{array}$ \\
\hline 8 & Extremely vulnerable & $>200$ & $0.0000-0.2225$ \\
7 & Strongly vulnerable & $180-199$ & $0.2225-0.3450$ \\
6 & Vulnerable & $160-179$ & $0.3450-0.4675$ \\
5 & & $140-159$ & $0.4675-0.590$ \\
4 & & $120-139$ & $0.5900-0.7125$ \\
3 & Weakly vulnerable & $100-119$ & $0.7125-0.8350$ \\
2 & & $80-99$ & $0.8350-0.9570$ \\
1 & Invulnerable & $<79$ & $>0.9570$ \\
\hline
\end{tabular}

TABLE 6. Comparison of aquifer vulnerabilities, as evaluated by the MCA, original DRASTIC and two modified DRASTIC models, based on the spatial distribution of vulnerability classes. For MCA and original DRASTIC, the distribution was quantified from Figures 8 and 7, respectively. For the Vector-DRASTIC and $\mathrm{NO}_{3}$-DRASTIC models the distribution was quantified from Figures 13 and 14 of Pacheco and Sanches Fernandes (2013), respectively.

\begin{tabular}{ccccc}
\hline & \multicolumn{5}{c}{ Method } \\
\cline { 2 - 5 } Vulnerability class & MCA & DRASTIC & Vector-DRASTIC & NO $_{3}$-DRASTIC \\
\cline { 2 - 5 } & 0.0 & 0.0 & 32.5 & 31.4 \\
\hline 1 & 22.6 & 7.4 & 12.2 & 14.6 \\
2 & 21.1 & 30.9 & 5.6 & 2.1 \\
3 & 4.8 & 11.7 & 0.0 & 1.4 \\
4 & 1.8 & 0.3 & 0.0 & 0.5 \\
6 & 0.0 & 0.0 & 0.0 & 0.2
\end{tabular}


ms_Text_final version

26 December 2014

\begin{tabular}{lllll}
7 & 0.0 & 0.0 & 0.0 & 0.0 \\
8 & 0.0 & 0.0 & 0.0 & 0.0 \\
\hline
\end{tabular}


ms_Text_final version

Appendix A - Quality parameters used in MCA (Table 2b) concerning spring water samples collected at the sites displayed in Figure 5 in September 2002. Source: Alencoão et al. (2003). Symbols: see Table $2 a$.

\begin{tabular}{|c|c|c|c|c|c|c|c|c|}
\hline & $\mathrm{pH}$ & $\mathrm{NO}_{3}^{-}$ & $\mathrm{Fe}$ & $\mathrm{Mn}$ & $\mathrm{Zn}$ & $\mathrm{Cu}$ & $\mathrm{SO}_{4}{ }^{2-}$ & Ec \\
\hline Spring site & & $\mathrm{mg} \mathrm{NO}_{3} / \mathrm{L}$ & $\mathrm{mg} / \mathrm{L}$ & $\mathrm{mg} / \mathrm{L}$ & $\mathrm{mg} / \mathrm{L}$ & $\mathrm{mg} / \mathrm{L}$ & $\mathrm{mg} \mathrm{SO}_{4} / \mathrm{L}$ & $(\mu \mathrm{S} / \mathrm{cm})$ \\
\hline 1 & 5.2 & 1.68 & 0.1 & 5.2 & 1.6 & 0.7 & 0.33 & 29.8 \\
\hline 2 & 5.2 & 2.48 & 0.1 & 1.3 & 2 & 1.2 & 1.07 & 33 \\
\hline 3 & 4.6 & 0.35 & 0.1 & 19.2 & 3.4 & 0 & 0.24 & 19 \\
\hline 4 & 4.5 & 1.99 & 0.1 & 31 & 7.2 & 0.3 & 0.57 & 25.4 \\
\hline 5 & 5.2 & 1.99 & 0.1 & 2 & 0 & 0.4 & 0.77 & 27.4 \\
\hline 6 & 5.8 & 0.58 & 0.1 & 1.7 & 0.6 & 0 & 0.64 & 21.5 \\
\hline 7 & 5.4 & 0.93 & 0.1 & 6.3 & 0 & 0 & 1.03 & 41.6 \\
\hline 8 & 4.9 & 24.01 & 0.1 & 46.5 & 5.5 & 0.4 & 5.13 & 123.4 \\
\hline 9 & 4.9 & 12.58 & 0.1 & 57 & 0.8 & 0 & 3.15 & 143.1 \\
\hline 10 & 5.1 & 5.89 & 0.1 & 3.1 & 3.8 & 4.3 & 0.83 & 41.8 \\
\hline 11 & 5.4 & 1.33 & 0.1 & 16.5 & 1.3 & 0.5 & 0.4 & 41.6 \\
\hline 12 & 5.9 & 2.52 & 0.1 & 0.3 & 0 & 0 & 0.47 & 29.2 \\
\hline 13 & 5 & 8.46 & 7.2 & 5.2 & 0.6 & 0 & 24.46 & 104.7 \\
\hline 14 & 4.9 & 1.37 & 0.1 & 5.7 & 1.2 & 0 & 0.51 & 22.9 \\
\hline 15 & 4.9 & 4.3 & 0.1 & 2 & 0.5 & 0 & 1.7 & 42 \\
\hline 16 & 5.8 & 3.68 & 0.1 & 1.8 & 1.5 & 0 & 0.44 & 38.7 \\
\hline 17 & 5 & 1.55 & 0.1 & 2.9 & 0 & 0.4 & 1.14 & 23.1 \\
\hline 18 & 5.8 & 3.23 & 0.1 & 3.3 & 0 & 0 & 2.16 & 49.4 \\
\hline 19 & 5.2 & 7.18 & 15 & 33 & 4.1 & 0 & 3 & 296 \\
\hline 20 & 4.9 & 1.64 & 0.1 & 10.4 & 0 & 0 & 0.65 & 33.3 \\
\hline 21 & 6.1 & 7.93 & 7.9 & 4.9 & 0.7 & 0.5 & 2.13 & 44.5 \\
\hline 22 & 5 & 76.58 & 22.4 & 9.9 & 10 & 0 & 22.52 & 316 \\
\hline 23 & 5.7 & 0 & 172.7 & 2.8 & 0 & 0 & 1.46 & 62 \\
\hline 24 & 6.3 & 0.27 & 5.6 & 0.2 & 0 & 0 & 0.88 & 58.5 \\
\hline 25 & 5.9 & 7.75 & 5.9 & 0.5 & 1.7 & 0.6 & 15.6 & 103.4 \\
\hline 26 & 5.8 & 5.45 & 6.1 & 1.4 & 2 & 0.6 & 18.35 & 92.7 \\
\hline 27 & 6.3 & 14.93 & 6.9 & 0.4 & 1.5 & 0.3 & 28.56 & 175.7 \\
\hline 28 & 6.7 & 0.13 & 0.1 & 0.3 & 2.5 & 0 & 2.43 & 67.9 \\
\hline
\end{tabular}


ms_Text_final version

26 December 2014

$\begin{array}{lllllllll}29 & 6.2 & 16.79 & 0.1 & 0.4 & 1.5 & 0.5 & 7.38 & 111.3 \\ 30 & 6.3 & 33.57 & 10.2 & 6.2 & 2.2 & 0.3 & 32.05 & 235 \\ 31 & 6.3 & 29.32 & 7.1 & 3.2 & 4 & 1.6 & 18.62 & 181.6\end{array}$


ms_Text_final version

26 December 2014

Figure captions

Figure 1. Location and slope map of River Sordo hydrographic basin.

Figure 2. Geology of the River Sordo basin. Adapted from Pacheco and Sanches Fernandes (2013).

Figure 3. Soil map of River Sordo basin. Source: Agroconsultores and Coba (1991).

Figure 4. Land use map of River Sordo basin, in 2007. Source: Corine Land Cover Map, available at http://www.igeo.pt.

Figure 5. Location of spring sites used for the measurement of groundwater quality parameters. The labels close to the points are in keeping with numbers in column 1 of Appendix A.

Figure 6. Flowchart illustrating the coupling of a reference method (DRASTIC) with a monitoring methods (MCA), executed with the purpose of delineating and updating aquifer vulnerability maps.

Figure 7. Aquifer vulnerability map based on the DRASTIC model. Adapted from Pacheco and Sanches Fernandes (2013).

Figure 8. Aquifer vulnerability map based on MCA.

Figure 9. Spatial distribution of vulnerability classes, as evaluated by DRASTIC, Vector-DRASTIC, $\mathrm{NO}_{3}$-DRASTIC and MCA. The meaning of vulnerability classes is in keeping with Table 5.

Figure 10. Quality status of Sordo lake water evaluated on the basis of quality data retrieved from http://snirh.pt. The sub-index values were estimated as described in the text (Section 3.4.2). The quality classes (A, B, C) are in keeping with Table 2a. Within the evaluation period (2000-2010), the status of Sordo lake water was predominantly very good (class B). 


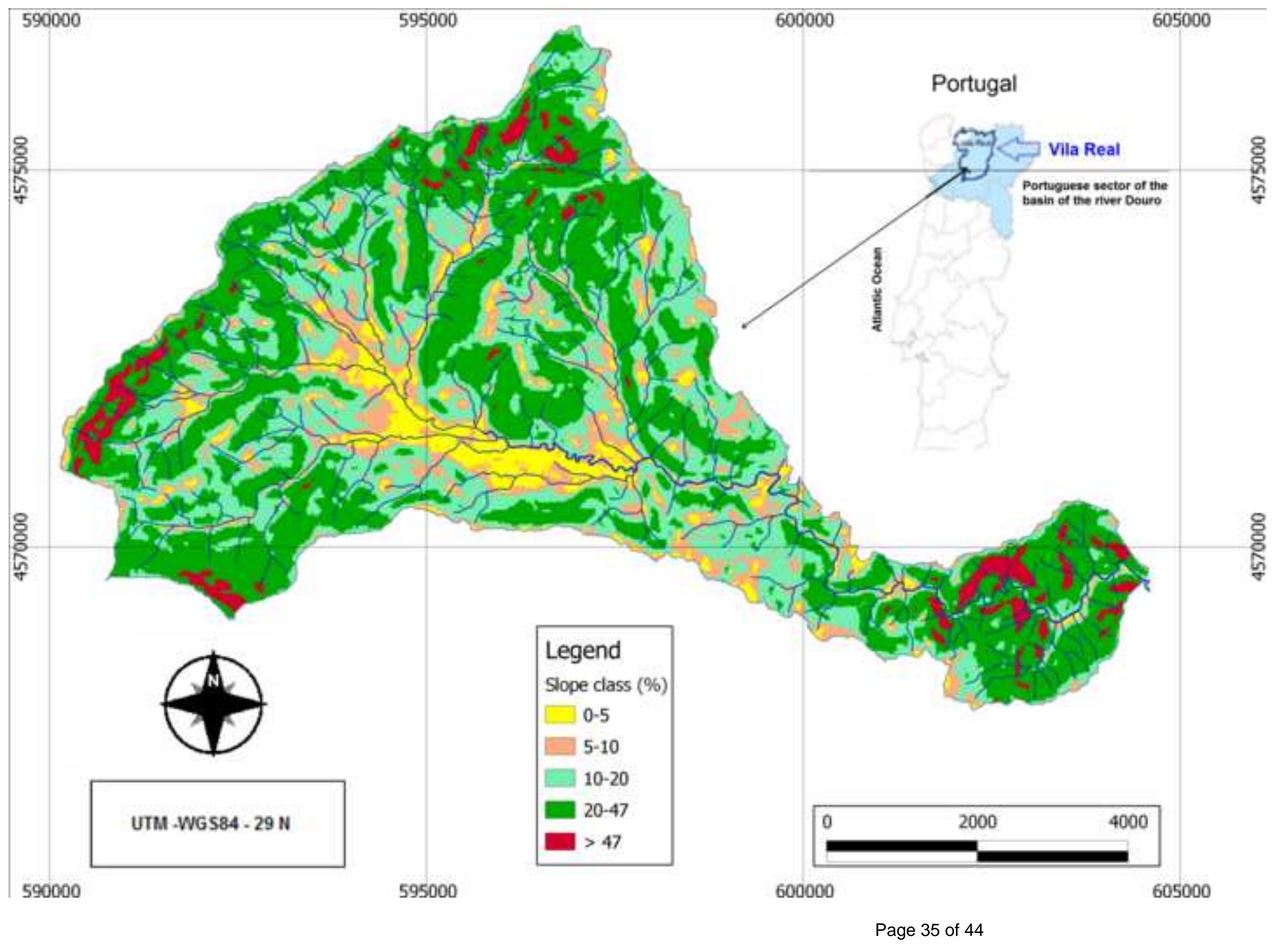

Page 35 of 44

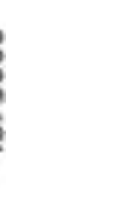

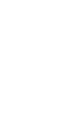

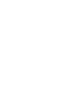




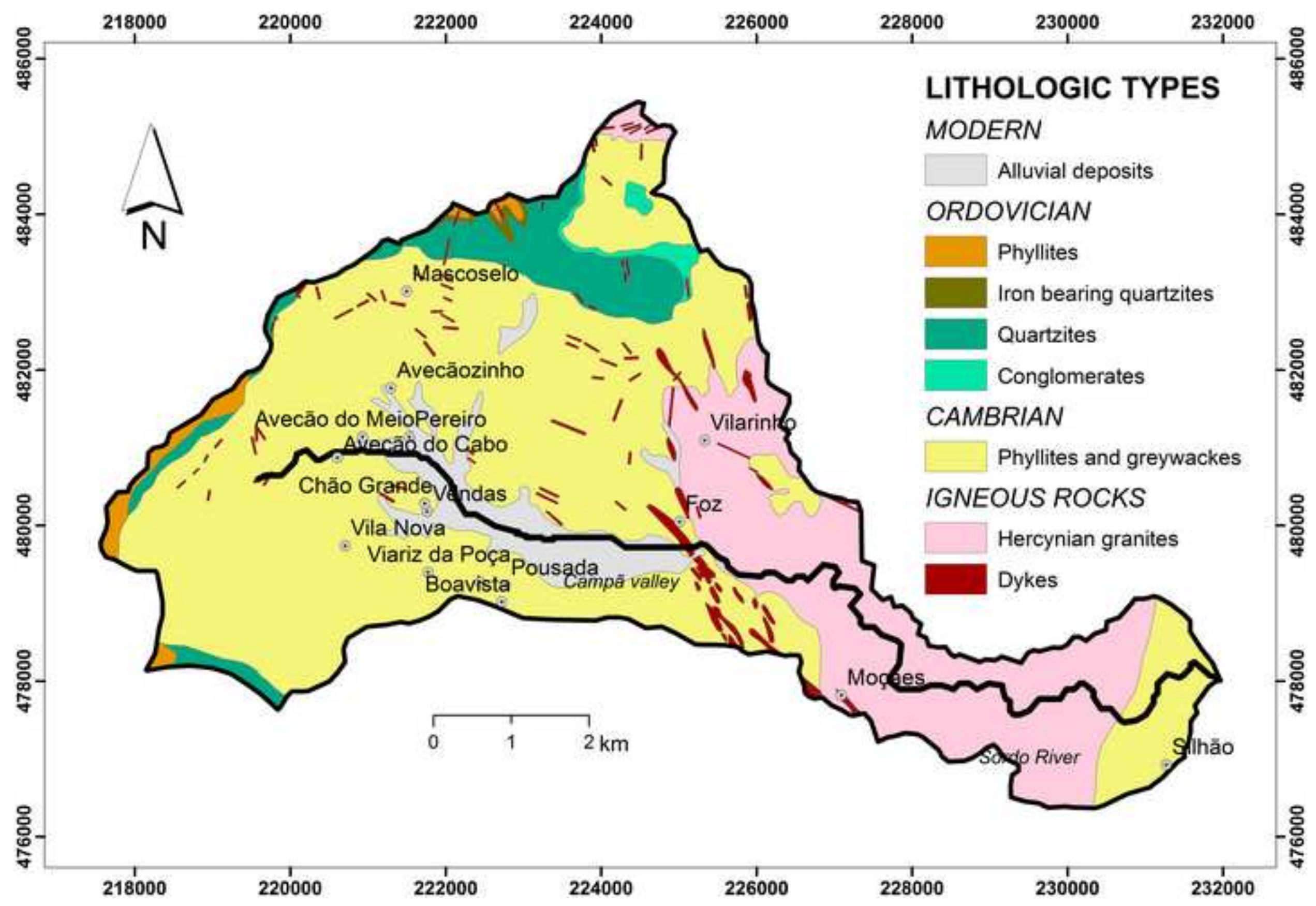

Page 36 of 44 


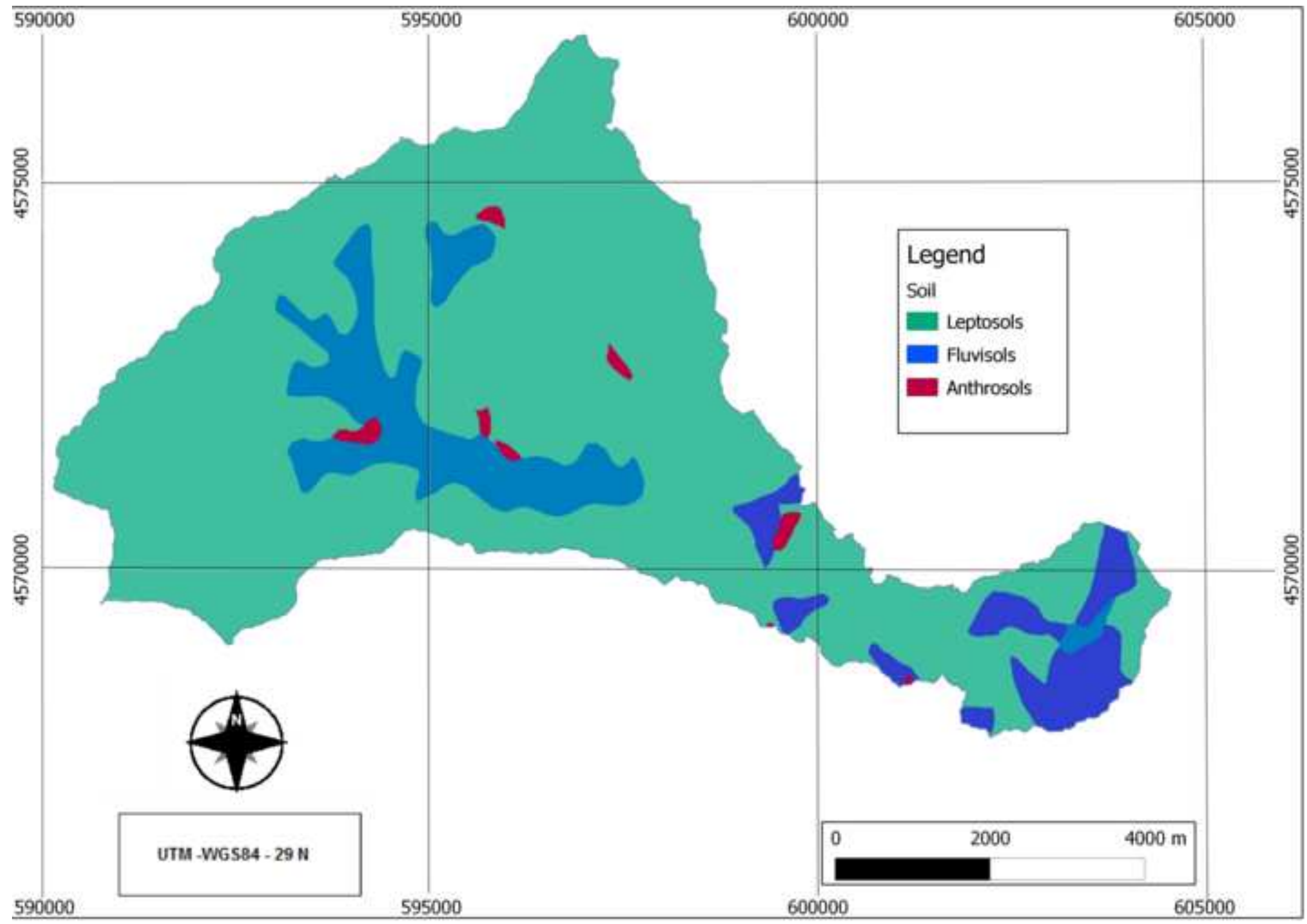

Page 37 of 44 


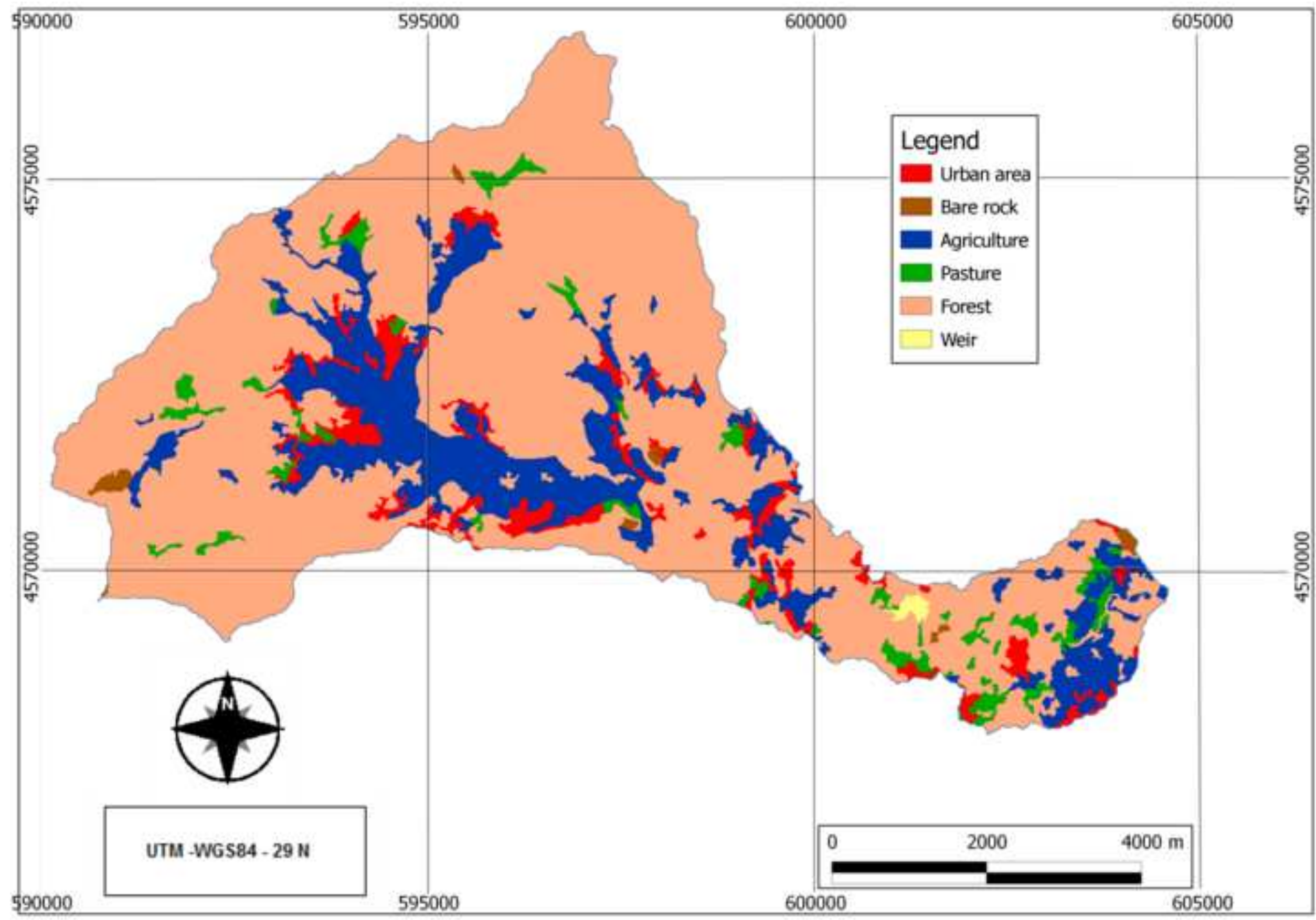

Page 38 of 44 


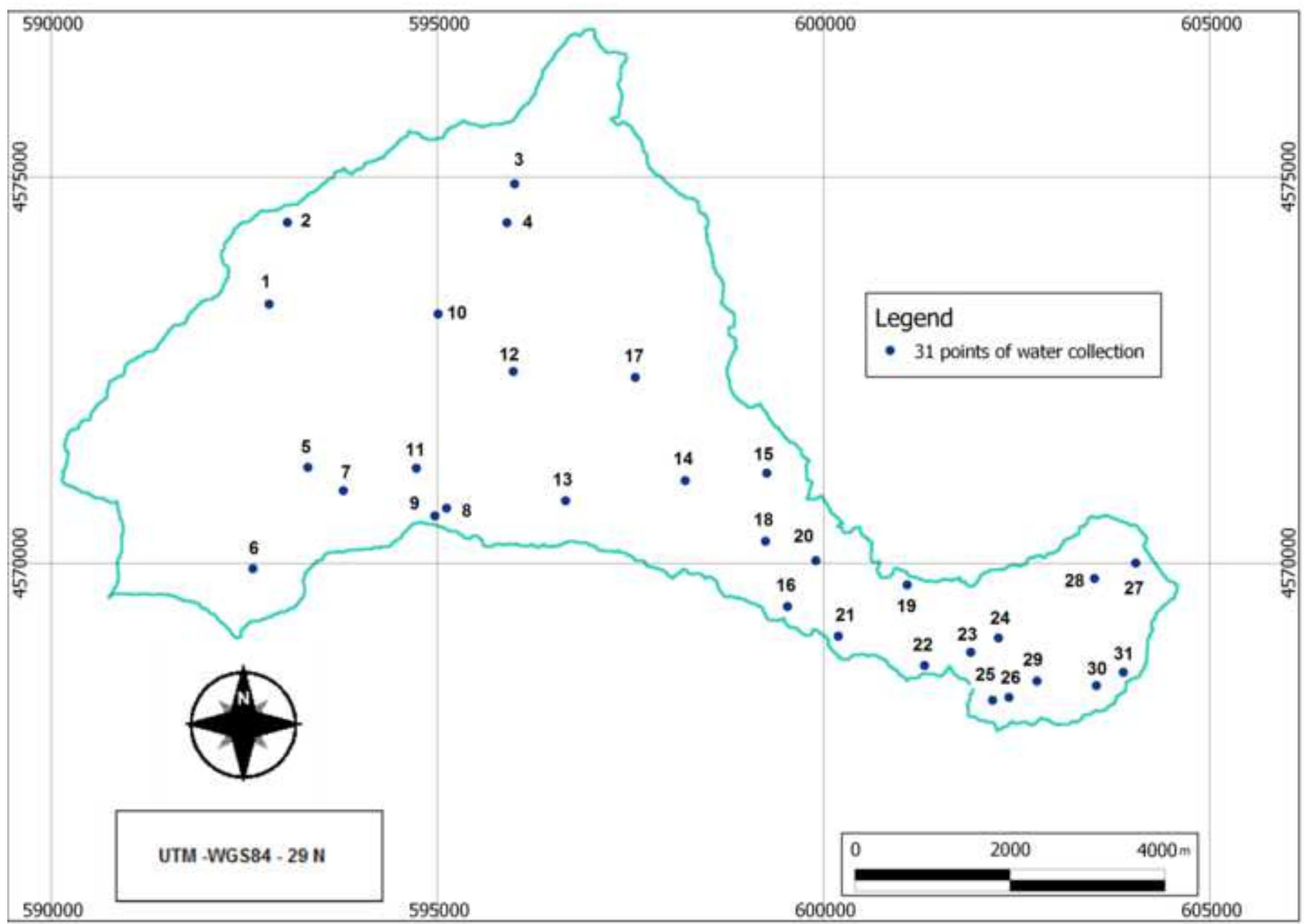

Page 39 of 44 
LAND USE
SURVEY
AQUIFER VULNERABILITY

EVALUATION

\section{GROUNDWATER}

QUALITY

MONITORING

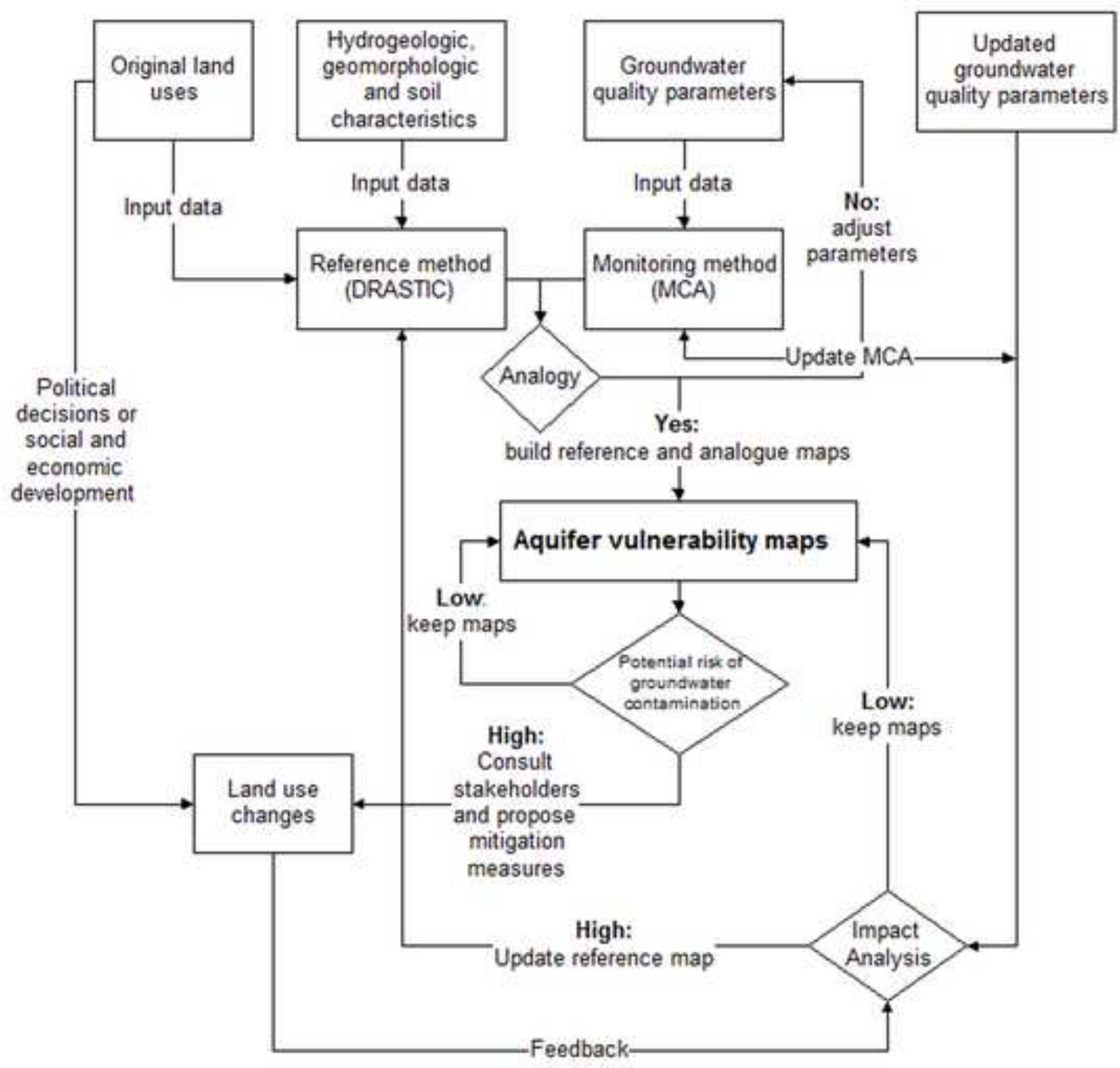




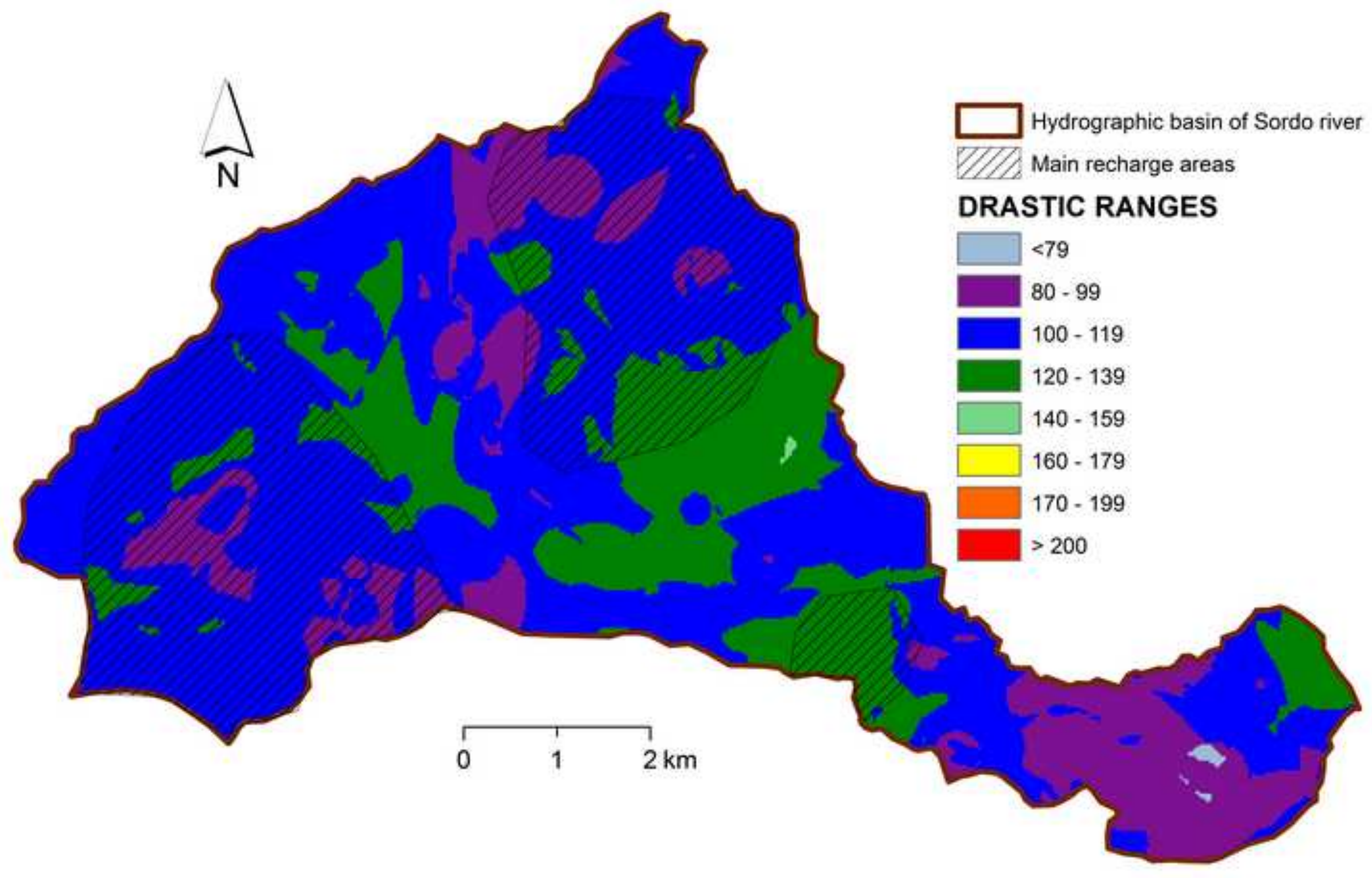




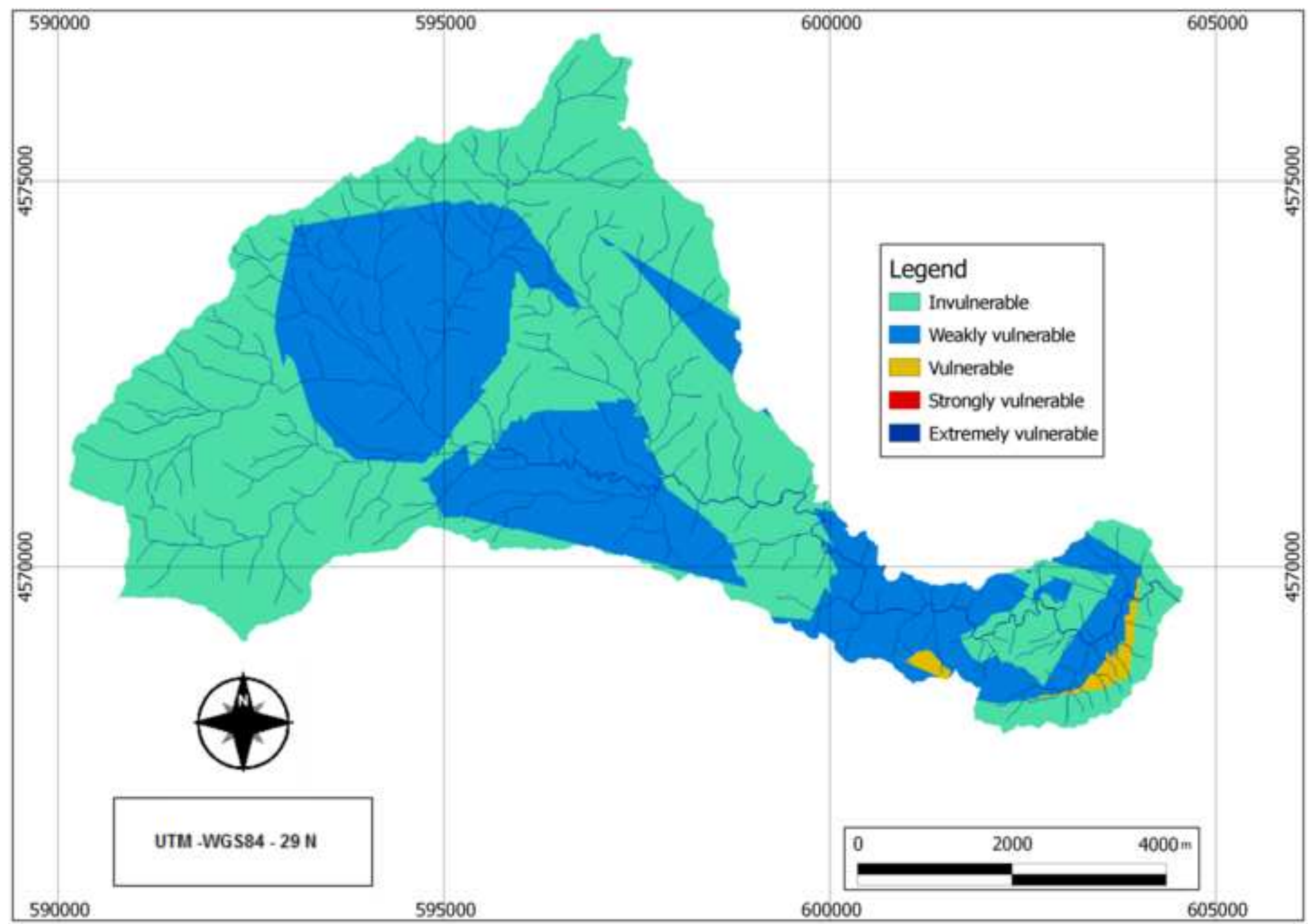

Page 42 of 44 


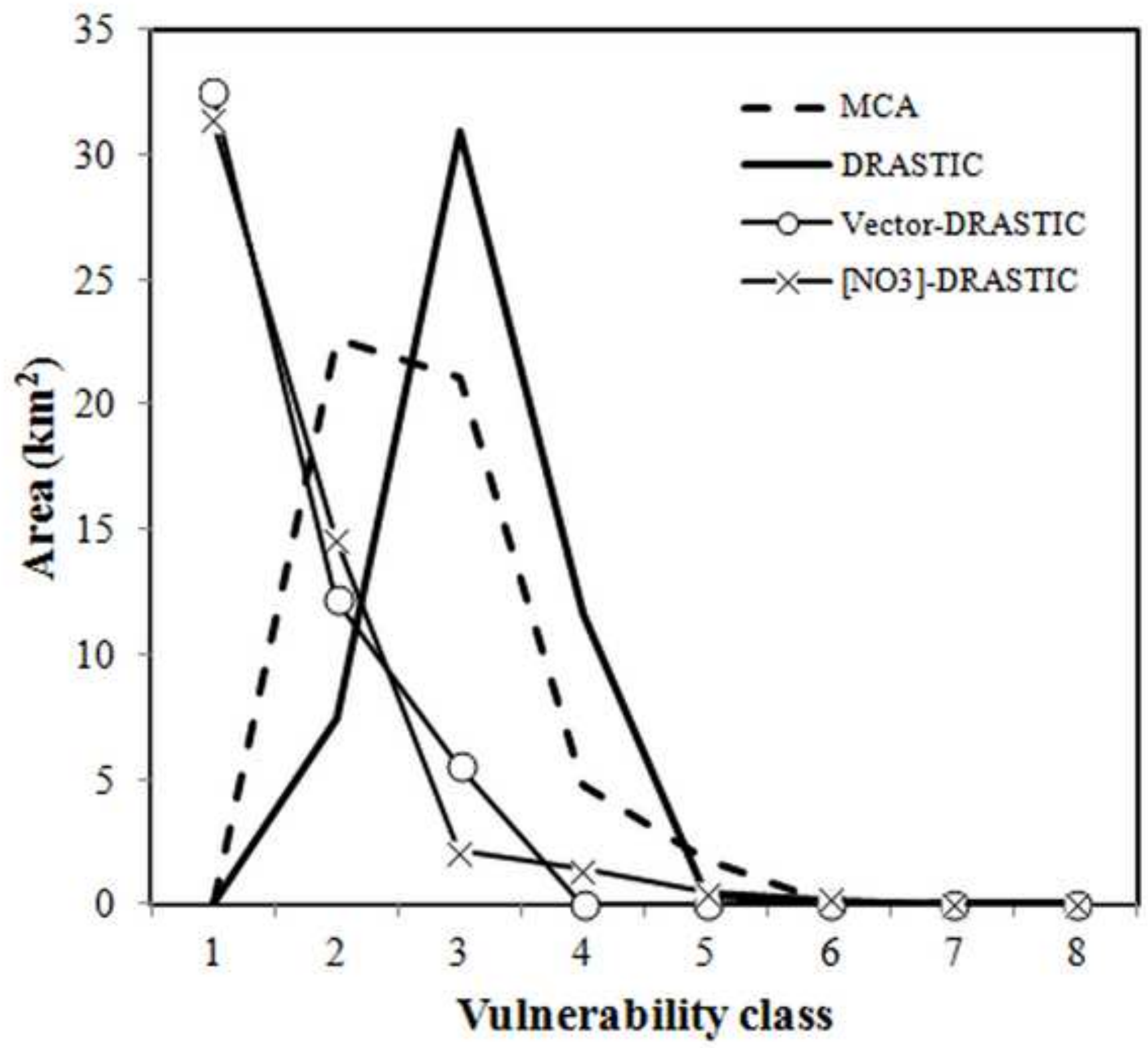

rage 43 or 44 


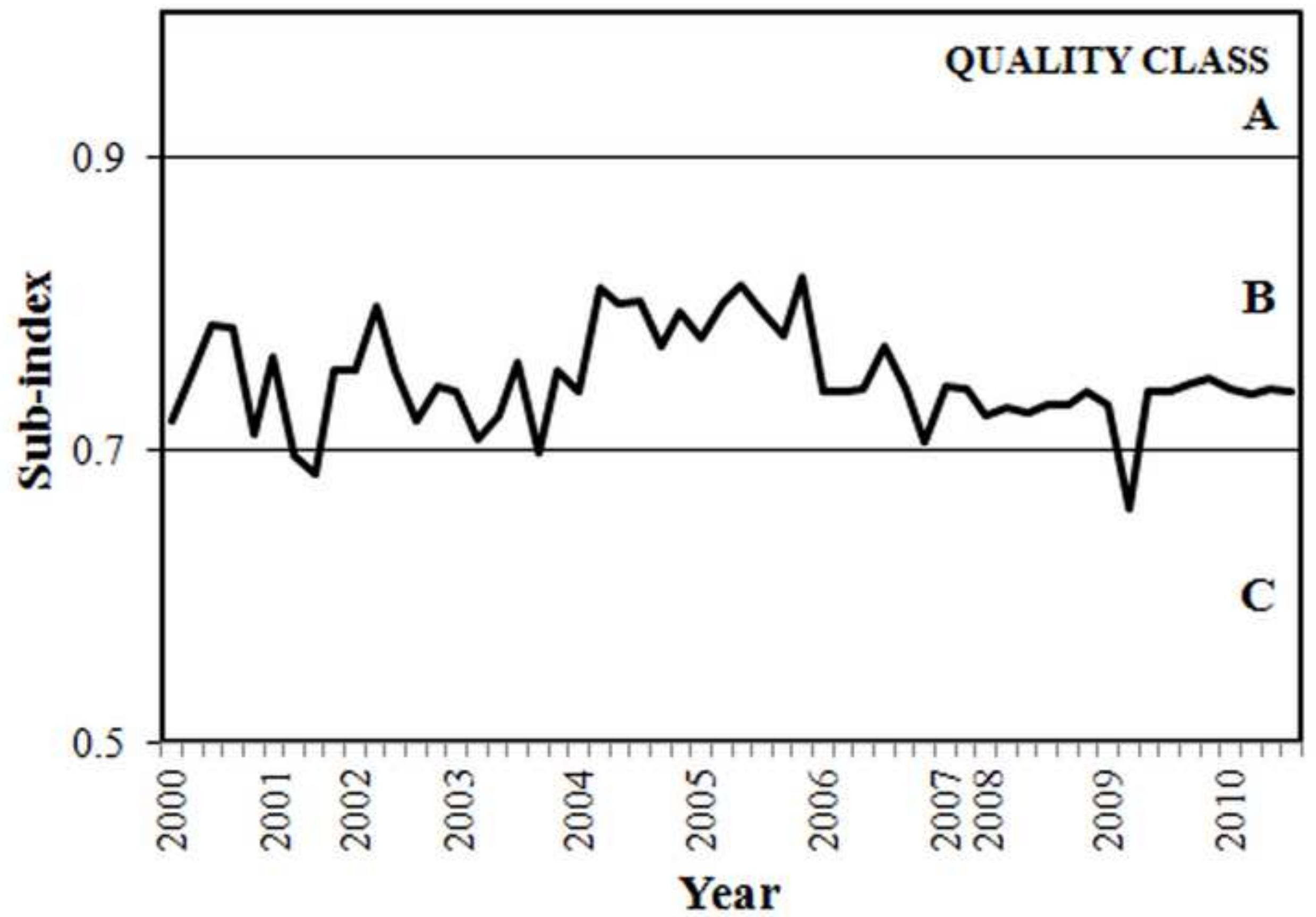

Page 44 of 44 